\title{
The Effect in Newborn Rabbits of Overfeeding on Fat Deposition, Gross Energetic Efficiency, and Metabolic Rate
}

\author{
S. A. SPENCER, J. VINTER, AND D. HULL \\ Department of Child Health, University Hospital, Queen's Medical Centre, Nottingham, England
}

\begin{abstract}
Newborn rabbits were overfed by encouraging them to suckle from two lactating does. Rabbits fed in this way (double fed) were compared with littermate controls (single fed) at age 7, 14, and 21 days. The double-fed rabbits gained weight more rapidly and at each age contained a higher percentage of fat than their single-fed counterparts. During the 1 st wh the double fed rabbits stored some of their extra fat in the cervical and interscapular adipose lobes. Double-fed rabbits utilized their feeds more efficiently than single fed rabbits in that they gained more weight per unit milk intake and their gross energetic efficiency was 10-20\% higher. In a second series of experiments oxygen consumption rate was measured in singleand double-fed rabbits at ages $7,14,21$, and 28 days. The relation between oxygen consumption and body weight were similar. We conclude that rabbits respond to overfeeding with an increased rate of weight gain associated with extra fat deposition, and this is associated with increased energy efficiency. (Pediatr Res 19: 127-130, 1985)
\end{abstract}

Adult animals usually are in energy balance, i.e. body weight and composition are constant, and the energy input from the diet equals the energy dissipated as heat. Animals maintain their energy balance by varying their food intake. In man there is a tendency for energy intake to exceed requirements with resultant weight gain and eventual obesity. Rothwell and Stock (9) induced rats to overfeed by offering them a varied and palatable diet (cafeteria fed), and they produced evidence to suggest that adolescent rats can moderate their energy balance by dissipating some of the excess energy input as heat (8). This "thermogenic" response to overfeeding has been termed dietary-induced thermogenesis (10) and evidence has been presented to show that it occurs in brown adipose tissue (8). These findings have been contested by others (7) who believe that any thermogenic response to overfeeding is small and is related to the metabolic cost of synthesising and laying down fat.

In most mammals brown adipose tissue is most active as a thermogenic organ in the immediate newborn period. One might anticipate that if it had a role in controlling energy balance, it would be most easily demonstrated at this stage. The aim of this study in newborn rabbits was to investigate the effect of overfeeding on growth, particularly with respect to the deposition of fat and the thermogenic activity of brown adipose tissue.

The studies are of some clinical interest. It is current practice

Received April 26, 1984; accepted September 5, 1984.

Correspondence Dr. S. A. Spencer, Department of Child Health, E Floor, East Block, University Hospital, Queen's Medical Centre, Nottingham NG7 2UH, England. to feed immature infants as much as they will tolerate via a nasogastric tube in an attempt to achieve intrauterine growth rate (11). Experience with recently developed formulae specially designed for the preterm infant has shown that growth rate may be significantly increased when these readily digestible feeds are used (6). With further developments it is likely that growth in some preterm infants will exceed intrauterine growth. In these cases it will be important to understand the implications for fat deposition and metabolic rate.

\section{METHODS}

The experiments were conducted on young rabbits from a colony of New Zealand White Californian cross-bred rabbits. Nursing does normally feed their young only once a day. Therefore the young can be separated after their first feed and nursed separately, provided they are returned to the mother for approximately $30 \mathrm{~min}$ each morning for feeding. In these experiments overfeeding was achieved by introducing the young rabbits to a second lactating doe 8-12 h after they had fed from their own mothers; as first described by Hardman et al. (4). Rabbits fed in this way will take twice as much milk as their normally fed littermates and are termed "double fed." Litter size was kept to a maximum of six animals and each double-fed rabbit was paired with a littermate of similar birth weight which acted as a singlefed control. During the first 8 days of life, the rabbits were nursed in incubators at $35.0^{\circ} \mathrm{C}$. Subsequently, they were transferred to straw-filled nesting boxes with their littermates.

In the first series of experiments the double-fed rabbits were killed after 7,14 , or 21 days. The single-fed animals were killed at $7,14,21$, or 28 days. The last group were of similar weight to the double-fed group at 21 days and this permitted a weight for weight comparison. Six animals in each of the identified groups were studied.

The milk intake of each rabbit was measured by weighing before and after every feed. This tends to underestimate milk intake because rabbits usually micturate while feeding. Energy intake was calculated by assuming that rabbit milk has a mean energy content of $0.866 \mathrm{MJ} / 100 \mathrm{~g}$. This figure is derived from published data based on the calorimetry of milk obtained from 12 Dutch rabbit does (1).

All the aforementioned rabbits plus six newborn rabbits were subjected to carcass analysis for water, fat, and energy. Prior to homogenization, the adipose tissue lobes were dissected out and weighed and the gut contents and fur were removed from the carcass. Each animal carcass was homogenized with twice its weight of water in a Waring Blendor. Samples of approximately $30 \mathrm{~g}$ were freeze dried so that the carcass water content could be estimated. The water estimations were performed in triplicate and the results obtained were subjected to an analysis of variance. The $95 \%$ confidence limits about the mean of each set of 
observations was $\pm 0.73 \%$, which indicates that the homogenate was adequately mixed and that the freeze drying process had been effective. The freeze-dried homogenate was used for analysis of fat and energy. Total triglycerides were measured in the homogenate and in the adipose lobes by extracting the triglycerides with chloroform/methanol $(2: 1, \mathrm{v}: \mathrm{v})$, hydrolyzing the lipid with alcoholic potassium hydroxide and estimating the glycerol released using the micromethod of Boehringer (Biochemia Test Combination). Gross energy was measured with a Parr Adiabatic Bomb Calorimeter. Samples were analysed in duplicate and the results subjected to an analysis of variance. The $95 \%$ confidence limits for the mean of each pair of results was $\pm 0.65 \mathrm{MJ}$.

The energy accumulated during life was estimated for the 42 rabbits described above. The mean carcass energy per unit body weight was calculated for the six newborn rabbits whose carcasses were analyzed. This value and the birth weights of the 42 rabbits was used to estimate the energy content of each rabbit in the newborn period. By subtracting the energy value of the newborn from the energy value of the carcass it was possible to estimate the energy accumulated in the tissues during life. The efficiency of growth was estimated for each animal by calculating the percentage of energy intake accumulated in the carcass during life.

In the second series of experiments, resting oxygen consumption was measured in six newborn and six single- and doublefed rats aged $7,14,21$, and 28 days. For this purpose the automated oxygen consumption apparatus was used as described by Elphick et al. (3). Measurements were made at the thermoneutral temperature. Rabbits were not fasted prior to measurement, because the rabbit stomach acts as a reservoir of food perfusing the gut continuously for over $24 \mathrm{~h}$ (1) and because we wished to include any dietary thermogenic effect in our measurements.

\section{STATISTICS}

Differences between groups of single- and double-fed rabbits were tested for statistical significance using Student's unpaired $t$ test. The relationship between oxygen consumption and body weight was linear in both single- and double-fed rabbits in the weight range $114-550 \mathrm{~g}$. The SEs of the slopes and intercepts of the regression lines were tested for statistically significant differences using Student's $t$ test.

\section{RESULTS}

The double-fed rabbits gained weight more rapidly than the single fed. The carcass weights of the animals analyzed are shown in Table 1. The mean weights for the carcasses of double-fed animals are very similar to the mean carcass weights of the singlefed animals which are 1 wk older. Therefore it is possible to compare single- and double-fed rabbits of similar body weights (but with different ages). The results of these composition analyses for fat are presented in Table 2. During normal growth the fat content of the body increased. At each age double-fed rabbits contain a higher proportion of fat than their single-fed counterparts. Comparison of single- and double-fed animals of similar body weight confirms that the double-fed rabbits contain more fat than is usual for their size.

The fat content data for the cervical and interscapular lobes (hereafter referred to as cervical) of adipose tissue in relation to body weight are presented in Figure 1. During the 1st wk, double- fed rabbits store an excess of fat in these lobes. Subsequently the fat content is the same in both groups in relation to body weight.

Weight gain in relation to milk intake is shown in Figure 2 for each week of life in all 42 rabbits studied. As rabbits were killed

Table 2. The effect of age and double feeding on body fat

\begin{tabular}{lccccc}
\multicolumn{7}{c}{$(n=6)$} \\
\hline Age (days) & 0 & 7 & 14 & 21 & 28 \\
\hline Body fat \% body weight (mean \pm SD) \\
Single fed & $3.3 \pm 0.7$ & $5.5 \pm 2.0$ & $6.7 \pm 1.4$ & $7.3 \pm 1.8$ & $6.5 \pm 2.4$ \\
Double fed & $8.8 \pm 1.3$ & $10.8 \pm 1.7$ & $11.0 \pm 1.9$ \\
$p$ & $<0.02$ & $<0.05$ & $<0.02$ \\
\hline
\end{tabular}

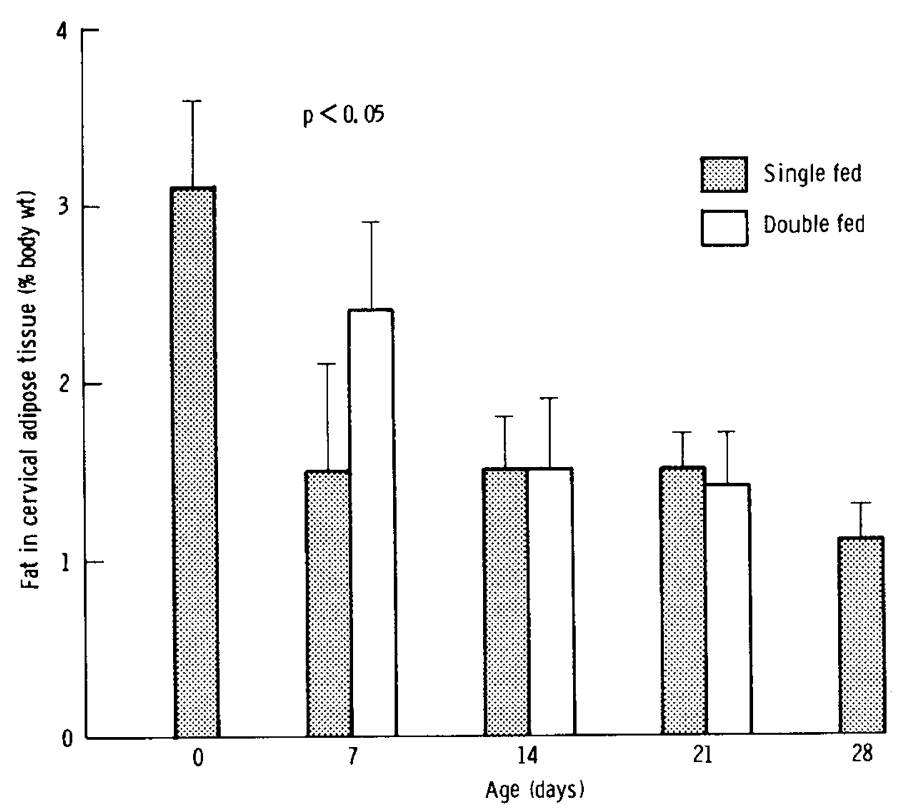

Fig. 1. The effect of age and double feeding on the mean fat content $\pm \mathrm{SD}$ of the cervical and interscapular adipose tissue as a proportion of body weight $(n=6)$.

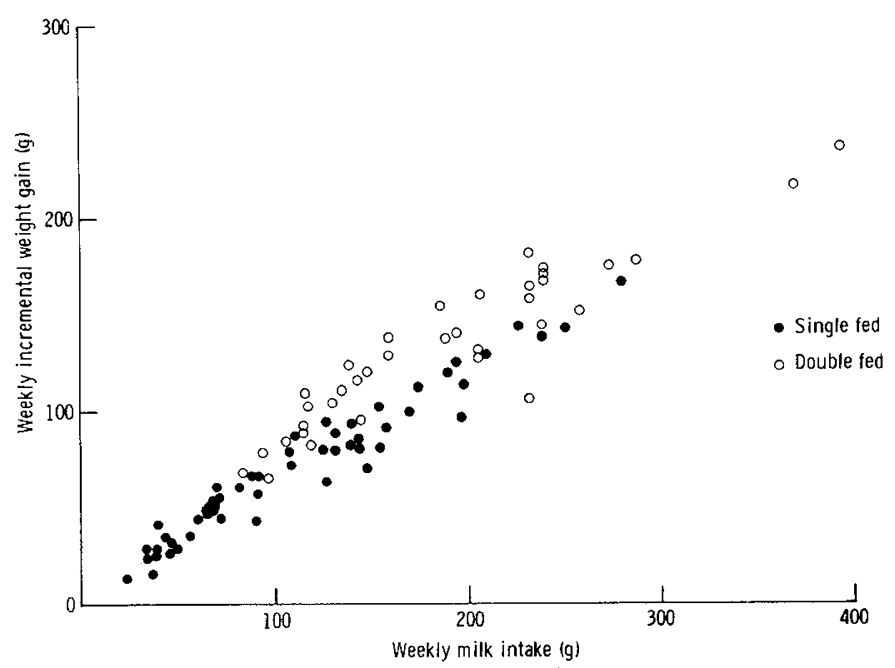

Fig. 2. The relation between incremental weight gain and weekly milk intake during each week of life in 42 rabbits.

Table 1. The effect of age and double feeding on carcass weight $(n=6)$

\begin{tabular}{cccccc}
\hline Age (days) & 0 & 7 & 14 & 21 & \\
\hline Carcass wt g (mean \pm SD) & & & & & \\
Single fed & $46.9 \pm 4.3$ & $95.6 \pm 14.9$ & $166.4 \pm 20.9$ & $261.2 \pm 44.4$ & $429.3 \pm 73.5$ \\
Double fed & & $158.5 \pm 19.6$ & $288.7 \pm 31.8$ & $429.7 \pm 60.5$ \\
$p$ & & $<0.001$ & $<0.001$ & $<0.001$ \\
\hline
\end{tabular}


each week, more data are available covering the earlier weeks of life. It appears that double-fed rabbits not only gain more weight than single-fed each week, but also they gain more weight per unit of milk intake. The impression that double-fed rabbits utilize their feed more efficiently is illustrated in Figure 3 where the efficiency of growth is shown to be greater during life for doublefed rabbits killed at 7, 14, or 21 days than for the single-fed controls.

Oxygen consumption in single- and double-fed rabbits in relation to body weight is shown in Figure 4 . There is no difference between results in single- and double-fed rabbits.

Two estimates of heat loss during life were made. The first estimate was made by assuming that the difference between energy intake and energy accumulated by the carcass represented energy lost as heat. The second estimate was made using the oxygen consumption data. The data were extrapolated to calculate oxygen consumed during life, assuming that the rate of consumption altered by equal increments between the ages at which it was measured. Oxygen consumption was converted to heat loss by assuming that 1 liter of oxygen has an energy value of $30.397 \mathrm{KJ}$. The two estimates are very similar (Table 3) indicating that the oxygen consumption measurements were indicative of a mean daily metabolic rate.

\section{DISCUSSION}

Some of the estimates in the present study are open to error. First, energy intake is underestimated because young rabbits almost invariably micturate while feeding; this leads to under-

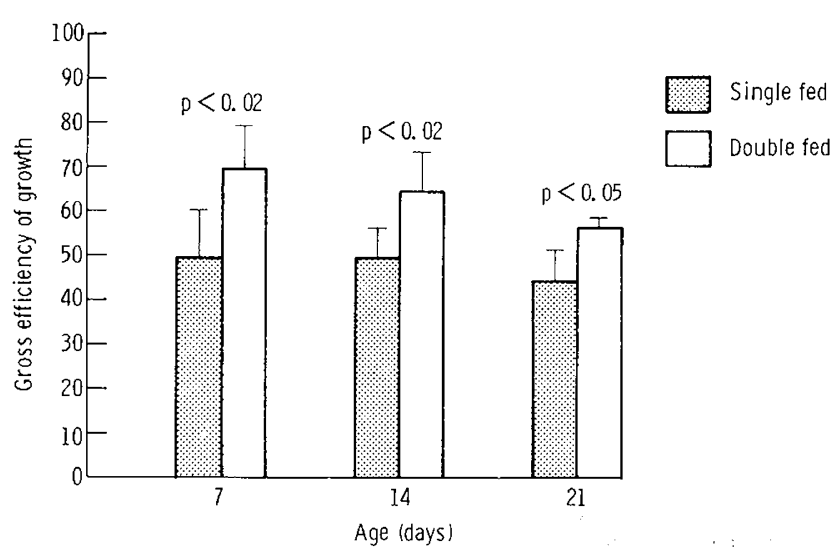

Fig. 3. The effect of double feeding on the mean gross energetic efficiency of growth \pm SD during the $1 \mathrm{st} \mathrm{wk}, 1 \mathrm{st} 2 \mathrm{wk}$, and $1 \mathrm{st} 3 \mathrm{wk}$ of life $(n=6)$.

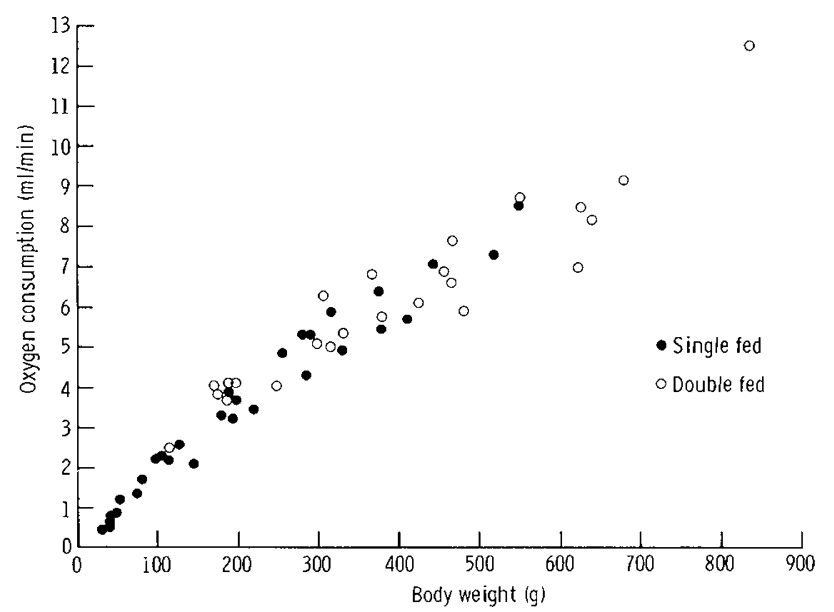

Fig. 4. The relation between oxygen consumption and body weight. There is no statistical difference between single and double fed rabbits with body weight between 114-550 g.
Table 3. The effect of double feeding on total heat loss during life $(n=6) ;$ two methods of calculation are presented for comparison

\begin{tabular}{lrll}
\hline Period (days) & $0-7$ & $0-14$ & $0-21$ \\
\hline Heat loss from carcass & energy data & MJ (Mean) \\
Single fed & 0.27 & 0.79 & 1.8 \\
Double fed & 0.36 & 1.1 & 2.4 \\
\multicolumn{4}{l}{} \\
Heat loss from oxygen consumption data MJ (mean) \\
Single fed & 0.31 & 0.85 & 1.7 \\
Double fed & 0.46 & 1.3 & 2.6 \\
\hline
\end{tabular}

measurement of milk intake. This error will inevitably lead to energy efficiency being overestimated. Nevertheless the comparison between single- and double-fed rabbits remains valid. Second, the estimate of heat loss, calculated from the difference between energy input and accumulated carcass energy, does not take urinary and fecal energy losses into consideration. The error due to urinary losses will be overcompensated by the undermeasurement of milk intake due to micturation, alluded to above. Fecal losses in milk fed rabbits are very small and so we think it unlikely that these errors will significantly affect the result. Third, the calculation of heat loss during life, based on the oxygen consumption measurements, are dependent on the 1-h measurments being representative of the animal's 24-h state. Measurements of metabolic rate over $24 \mathrm{~h}$ in rabbits show little fluctuation (E. M. Hey, D. Hull, unpublished data), presumably because of the unique way in which milk is stored in the stomach and gradually released over $24 \mathrm{~h}$, minimizing fluctuations due to the thermogenic effect of food. Furthermore, the estimating of heat loss during life from the carcass energy data and the oxygen consumption data are remarkably similar; this suggests that both estimations are valid.

There have been very few studies concerned with the energy efficiency of milk feeds in neonatal animals with which this work can be compared. Davies et al. (1) found that normally fed Dutch rabbits retained $27 \%$ of their energy intake during the 3 rd- 11 th day of life. This contrasts with $47 \%$ efficiency for single-fed rabbits during the first 7 days of life. The methods of estimating energy intake were similar but rabbits in Davies' study were not kept in a thermoneutral environment. Therefore energy would have been required to maintain body temperature. It has been shown that rabbits reared in a thermoneutral environment gain weight faster than those reared at $30^{\circ} \mathrm{C}(5)$.

We have shown that neonatal rabbits respond to a high energy intake by gaining weight rapidly and laying down extra adipose tissue. Overfeeding did not give rise to an increase in metabolic rate over and above that which was appropriate for weight. As a result a greater proportion of the energy intake was assimilated, leading to an increase in energy efficiency. Dietary-induced thermogenesis leads to a reduction in energy efficiency in overfed animals (8). Young rabbits are well endowed with brown adipose tissue and respond thermogenically to a cold environment (2). Double-fed rabbits were overfed to the point of accumulating extra fat, some of which was laid down in the brown adipose lobes. Therefore double-fed rabbits had the means and the stimulus for dietary-induced thermogenesis, but there was no evidence to suggest that it occurred.

If these results in rabbits are applicable to the human infant, then overfeeding premature infants is likely to be associated with accelerated growth and extra deposition of adipose tissue. Metabolic rate is unlikely to rise above that which is appropriate for the infant's weight and therefore a large rise in oxygen consumption would not be anticipated. This is reassuring, as some very low birth weight infants have chronically compromised respiratory function.

\section{REFERENCES}

1. Davies JS, Widdowson EM, McCance RA 1964 The intake of milk and retention of its constituents whilst the newborn doubles its weight. $\mathrm{Br} \mathrm{J}$ Nutr 
18:385-392

2. Dawkins MJR, Hull D 1964 Brown adipose tissue and the response of newborn rabbits to cold. J Physiol 172:216-238

3. Elphick MC, Johnson F, Taylor M, Davis WL 1981 An automatic oxygen consumption apparatus for small laboratory animals. Med Biol Eng Comput 19:110-116

4. Hardman MJ, Hull D, Oyesiku J 1970 The influence of birth weight and nutrition on postnatal growth of rabbits. Biol Neonate 66:306-312

5. Hardman MJ, Hull D, Oyesiku J 1970 A comparison of the growth of white and brown adipose tissue in rabbits reared under controlled conditions. Biol Neonate 16:354-361

6. Hendrickse WA, Spencer SA, Roberton DM, Hull D 1984 The calorie intake and weight gain of low birth weight infants fed on fresh breast milk or a special formulae diet. Eur J Paediatr, in press

7. Hervey GR, Tobin G 1983 Luxuskonsumption, diet-induced thermogenesis and brown fat: a critical review. Clin Sci 64:7-18

8. Rothwell NJ, Stock MJ 1979 A role for brown adipose tissue in diet induced thermogenesis. Nature 281:31-35

9. Rothwell NJ, Stock MJ 1982 Effects of feeding a palatable 'cafeteria' diet on energy balance in young and adult lean $(+/$ ?) Zucker rats. Br J Nutr 47:461

10. Rothwell NJ, Stock MJ 1983 Luxuskonsumption, diet-induced thermogenesis and brown fat: the case in favour. Clin Sci 64:19-23

11. Spencer SA, Hendrickse W, Roberton D, Hull D 1982 Energy intake and weight gain of very low birthweight babies fed raw expressed breast milk. $\mathrm{Br}$ Med J 285:924-926

\title{
Gestational Changes in the Germinal Matrix of the Normal Rhesus Monkey Fetus
}

\author{
NICHOLAS J. LENN and LEANNA WHITMORE \\ Departments of Neurology and Pediatrics, and the Clinical Neuroscience Research Center, University of Virginia, \\ Charlottesville, Virginia 22908
}

\begin{abstract}
To explain the reported predisposition to germinal matrix hemorrhage in premature infants, pathogenetically important morphological features of the germinal matrix should be present in the 3rd trimester and rapidly change near term. Such features were sought in this study of the germinal matrix and its vasculature in normal rhesus monkey fetuses. The matrix cells, glia, ependyma, and capillaries showed no important structural changes during the 3 rd trimester. The terminal vein tributaries were greatly enlarged by 148 days, but cellular and collagen support in their walls was minimal at this time. The latter features developed by the final days of gestation. These findings do not support a structural immaturity or specialization of the germinal matrix predisposing to germinal matrix hemorrhage. Our results, therefore, support the recent emphasis on physiological parameters in the pathogenesis and prevention of germinal matrix hemorrhage. (Pediatr Res 19:130-135, 1985)
\end{abstract}

\section{Abbreviation}

GMH, germinal matrix hemorrhage

GMH is well-known to have an age-related incidence. Premature infants have shown rates up to $40 \%$ (10), while in term babies such hemorrhages are uncommon (15). The gross correlation with the presence and subsequent disappearance of the germinal matrix near term in the human is an obvious explanation for these observations. However, it does not give any positive understanding of possible predisposing factors underlying the

Received December 15, 1983: accepted July 11, 1984

Address for correspondence Dr. Nicholas J. Lenn, Department of Neurology, Box 394, University of Virginia, Charlottesville, VA 22908.

Supported in part by NIH Grants HD NS 08658 and RR000169. occurrence of $\mathrm{GMH}$, nor any rational guidance to efforts at prevention $(4,10,12,15)$. In studies on this question, in addition to considerable attention to physiological parameters, anatomical predisposing factors have been described or suggested. Using postmortem perfusion and light microscopy, rupture along capillaries, and at capillary-venous junctions, but not at the larger veins was observed in human pathological material $(4,12)$. Several authors have suggested that anatomical features of capillary immaturity, mainly size and thinness of endothelium, may be important in the pathogenesis of $\operatorname{GMH}(4,10)$. In contrast, others have found and illustrated terminal vein rupture in similar material (6). In addition to the limited resolution of light microscopy, the preservation of the material in all such studies was necessarily compromised by the hemorrhages and by postmortem changes. Another approach is to use normal, well-fixed material from an appropriate experimental animal, rhesus monkey. Although actual hemorrhage is not present, the hypothesis can be stated as follows: if the age-related incidence of GMH is due to structural features of the germinal matrix or its vasculature, these would be present in the latter part of gestation, and disappear by term.

\section{MATERIALS AND METHODS}

The specimens were products of timed, uncomplicated pregnancies, delivered by hysterotomy under general anesthesia by the veterinary staff of the California Regional Primate Center. The 15 fetuses studied were of gestational ages (days): 60, 62, 77, $90,91,106,120$ (three cases), 132 (two cases), 133, 148 (two cases), and 162. This spans the 2 nd and 3rd trimesters up to 3 days prior to term. For clarity, age differences of 1-2 days are ignored in this report. Available body and brain weights were normal, indicating that the fetuses were healthy (5). While the animals were still anesthetized, they were perfused through the heart with a mixture of $1 \%$ paraformaldehyde and $1.25 \%$ glutaraldehyde in $0.1 \mathrm{M}$ sodium cacodylate $(\mathrm{pH} \mathrm{7.2)}$ at room temper- 